ARTICLE

DOI: $10.1038 /$ s41467-018-03296-8 OPEN

\title{
Wing bone geometry reveals active flight in Archaeopteryx
}

\author{
Dennis F.A.E. Voeten ${ }^{1,2}$, Jorge Cubo ${ }^{3}$, Emmanuel de Margerie ${ }^{4}$, Martin Röper ${ }^{5,6}$, Vincent Beyrand (1) ${ }^{1,2}$,
} Stanislav Bureš ${ }^{2}$, Paul Tafforeau (iD ${ }^{1}$ \& Sophie Sanchez (1D) ${ }^{1,7}$

Archaeopteryx is an iconic fossil taxon with feathered wings from the Late Jurassic of Germany that occupies a crucial position for understanding the early evolution of avian flight. After over 150 years of study, its mosaic anatomy unifying characters of both non-flying dinosaurs and flying birds has remained challenging to interpret in a locomotory context. Here, we compare new data from three Archaeopteryx specimens obtained through phase-contrast synchrotron microtomography to a representative sample of archosaurs employing a diverse array of locomotory strategies. Our analyses reveal that the architecture of Archaeopteryx's wing bones consistently exhibits a combination of cross-sectional geometric properties uniquely shared with volant birds, particularly those occasionally utilising short-distance flapping. We therefore interpret that Archaeopteryx actively employed wing flapping to take to the air through a more anterodorsally posteroventrally oriented flight stroke than used by modern birds. This unexpected outcome implies that avian powered flight must have originated before the latest Jurassic.

\footnotetext{
${ }^{1}$ European Synchrotron Radiation Facility, 71 Avenue des Martyrs, CS-40220, 38043 Grenoble Cedex, France. ${ }^{2}$ Department of Zoology and Laboratory of Ornithology, Palacký University, 17. listopadu 50, 77146 Olomouc, Czech Republic. ${ }^{3}$ Sorbonne Université, CNRS-INSU, Institut des Sciences de la Terre Paris, ISTeP UMR 7193, F-75005 Paris, France. ${ }^{4}$ CNRS, Laboratoire d'éthologie animale et humaine, Université de Rennes 1, Université de Caen Normandie, 263 Avenue du Général Leclerc, 35042 Rennes, France. ${ }^{5}$ Bürgermeister-Müller-Museum, Bahnhofstrasse 8, 91807 Solnhofen, Germany. ${ }^{6}$ Bayerische Staatssammlung für Paläontologie und Geologie, Richard-Wagner-Str. 10, D-80333 München, Germany. ${ }^{7}$ Science for Life Laboratory and Uppsala University, Subdepartment of Evolution and Development, Department of Organismal Biology, Evolutionary Biology Centre, Norbyvägen $18 \mathrm{~A}$, 75236 Uppsala, Sweden. Correspondence and requests for materials should be addressed to D.F.A.E.V. (email: dennis.voeten01@upol.cz)
} 
T he earliest phases of avian evolution and development of avian flight remain obscured by the rarity of representative fossil material and consequential limited phylogenetic resolution ${ }^{1}$. As the oldest potentially free-flying avialian known ${ }^{1-}$ ${ }^{3}$, Archaeopteryx represents the prime candidate to consider in resolving the initial chapter of bird flight. Although the traditional dichotomy between an arboreal and a cursorial origin of avian flight ${ }^{4}$ has relaxed towards the consideration of intermediate perspectives ${ }^{3,5}$, the question whether the first flying bird-line dinosaurs took flight under their own power remains unanswered.

Skeletal adaptations that structurally accompany known locomotor modes provide reliable proxies for inferring the habits of extinct tetrapods. The cross-sectional geometry of limb bones is largely determined by evolutionary selection on the interplay between strength and weight ${ }^{6}$ and continuous morphological and structural adaptation to the biomechanical loading regimes experienced during life ${ }^{7}$. Therefore, the avian wing skeleton informs on this stress regime through the application of beam theory mechanics ${ }^{8-10}$.

Although the value of exceptional and rare fossils discourages physical cross-sectioning, Propagation Phase-Contrast Synchrotron X-Ray Microtomography (PPC-SR $\mu \mathrm{CT}$ ) now offers nondestructive alternatives ${ }^{1}$. Using PPC-SR $\mu \mathrm{CT}$ at the European Synchrotron Radiation Facility with a novel data acquisition protocol (Supplementary Note 1), we visualised complete circa mid-diaphyseal humeral and ulnar cross sections of three Archaeopteryx specimens (Fig. 1a-h) because these elements exhibit the strongest flight-related biomechanical adaption in the modern avian brachium ${ }^{10,12}$. Their full transverse cross-sectional geometry was reconstructed (Fig. 1i-n) and compared with an extensive set of archosaurian humeri and ulnae representing 69 species spanning a wide variety of locomotory behaviours (Supplementary Fig. 1 and Supplementary Data 1). Notably, we included the basal "long-tailed" pterosaur Rhamphorhynchus and the derived "short-tailed" pterosaur Brasileodactylus in our archosaurian reference set to contrast conditions associated with pterosaurian volancy against those of the independently arisen avian flight apparatus. Although the pterosaurian and avian flight apparatus differ in fundamental morphological aspects, comparing them may be expected to reveal underlying analogous adaptations in wing bone geometry.

Raw virtual slice data revealed that the long-bone cortex of Archaeopteryx exhibits a vascular density in the range of modern birds, which proposes substantial metabolic performance. Cortical vascular density strongly varies between two specimens of Archaeopteryx studied, which we interpret, based on body size differences, to reflect ontogenetic disparity. Relative cortical thickness of archosaurian anterior limb bones successfully discriminates between known non-volant and volant forms, and confidently indicates that Archaeopteryx was volant. Massnormalised torsional resistance in the same set of limb bones describes a gradient within modern volant birds that ranges from flight strategies relying on occasional or intermittent flapping to gain altitude to hyperaerial specialists employing prolonged gliding or soaring in their flight. The three specimens of Archaeopteryx were found to unanimously ally with birds that incidentally employ flapping flight to evade predators or cross physical barriers, through which we interpret that Archaeopteryx actively used its wings to take to the air. Since the morphology of the flight apparatus in Archaeopteryx is known to be incompatible with the flight stroke executed by modern volant birds, we furthermore conclude that Archaeopteryx adopted a different flight stroke than used by birds today. Finally, we found that the evolution from primitive long-tailed pterosaurs to more derived short-tailed pterosaurs was accompanied by qualitatively comparable modifications to wing bone geometry as those that distinguish
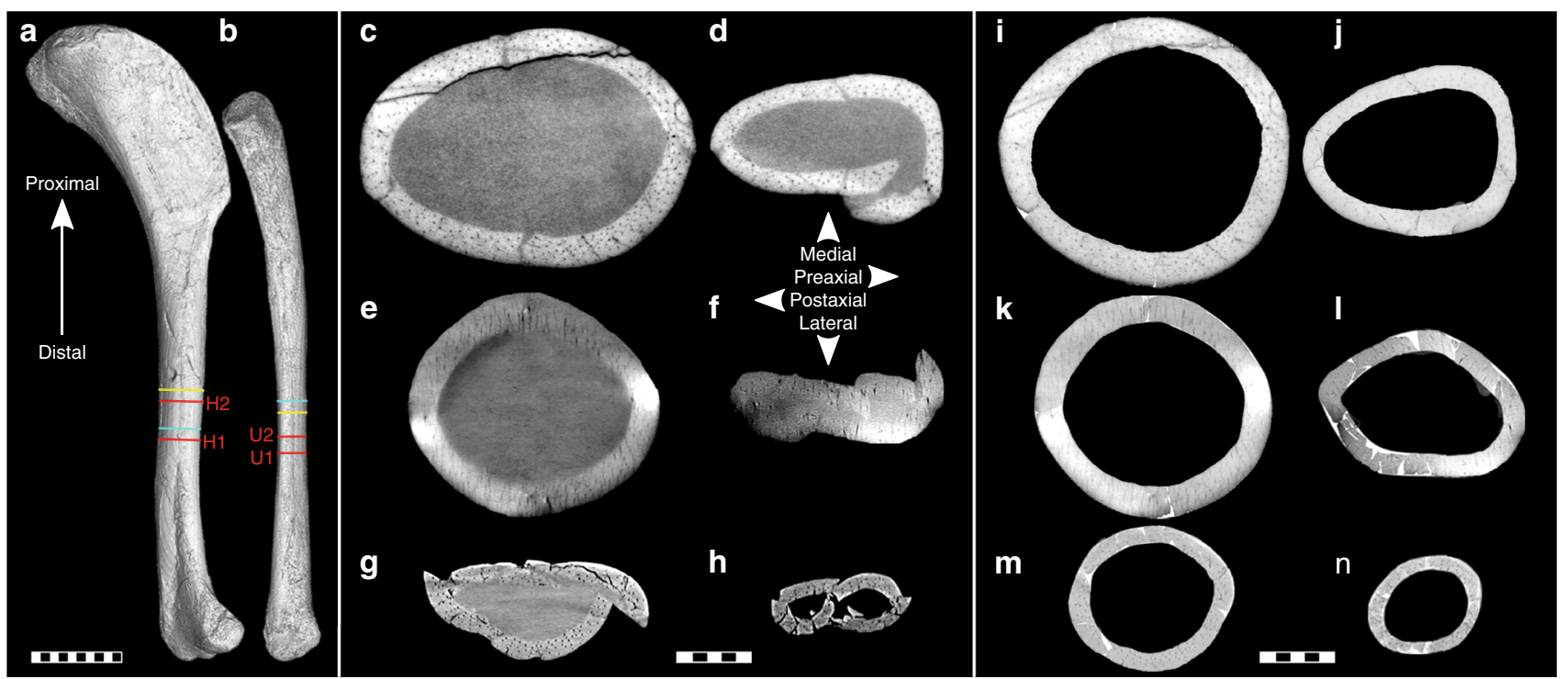

Fig. 1 Archaeopteryx humeral and ulnar virtual cross sections used in this study. a Right humerus and $\mathbf{b}$ right ulna of the ninth (Bürgermeister-Müller) specimen in lateral, respectively, medial view, with virtual sampling locations (red) and relative sampling locations in seventh (Munich) specimen (light blue) and fifth (Eichstätt) specimen (yellow). c-h Virtual cross sections, as preserved, with optimised intraosseous contrast, of (c) right humerus (H2) and (d) right ulna (U2) of ninth specimen, (e) right humerus and (f) right ulna of seventh specimen, and ( $\mathbf{g}$ ) left humerus and (h) left ulna of fifth specimen. i-n Reconstructed cross-sectional geometry, with optimised contrast of bone margins, of (i) humerus and (j) ulna of ninth specimen, ( $\mathbf{k}$ ) humerus and (I) ulna of seventh specimen, and ( $\mathbf{m})$ humerus and (n) ulna of fifth specimen; pure white indicates supplemented fragments. Morphological orientation applies to all sections (c-h). Scale bar (a, b) $10 \mathrm{~mm}$; scale bars $(\mathbf{c}-\mathbf{n}) 1 \mathrm{~mm}$ 
Archaeopteryx and principally flapping birds from hyperaerial birds, respectively.

\section{Results}

Cortical vascularisation. Contrary to previously reported data ${ }^{13}$, the bone cortex of Archaeopteryx is well vascularised (Fig. 1c-h, Supplementary Data 1). The ninth specimen exhibits an average cortical vascular density (Supplementary Fig. 2) in the lower range of neognaths (circa 69 canals $/ \mathrm{mm}^{2}$ ), but higher than the hoatzin (Opisthocomus hoazin; circa 43 canals $/ \mathrm{mm}^{2}$ ), whereas the average cortical vascular density of the smaller fifth specimen is higher than in most neognaths assessed (circa 116 canals $/ \mathrm{mm}^{2}$; Supplementary Fig. 3). This is consistent with a higher bone growth rate ${ }^{14}$ and associated higher resting metabolic rate ${ }^{15}$ than inferred from nearly avascular bone chips of the seventh speci$\mathrm{men}^{13}$. Ontogenetic progression is accompanied by a reduction in the apposition rate and vascular density of forming bone ${ }^{16}$. Providing that the fifth and ninth specimen represent the same species or that we are observing the shared generic ontogenetic pattern, their marked differential vascular density scaling inversely with body size would indicate disparate ontogenetic stages for these individuals.

Relative cortical thickness. Average relative cortical thickness of anterior limb bones successfully separates volant from non-volant archosaurs in our data set, although individual element values may slightly cross the average relative cortical thickness value of 0.60 found to separate these groups (Supplementary Figs. 4 and 5). Within non-volant groups, aquatic and (facultatively) quadrupedal species have relatively thicker humeral bone cortices than terrestrial bipeds. The basal pterosaur Rhamphorhynchus exhibits an average relative cortical thickness in the upper range of volant archosaurs, whereas the pterodactyloid pterosaur Brasileodactylus presents the lowest relative cortical thickness recorded. Only volant birds that engage in wing-propelled diving may exhibit an average relative cortical thickness in the range of non-volant archosaurs to counteract buoyancy and manage the demands of subaqueous locomotion ${ }^{17}$. Charadriiformes (Supplementary Fig. 1) share an elevated average relative cortical thickness with respect to other orders of flying birds (Supplementary Data 1, Supplementary Fig. 6), likely as an adaptation to negotiate "strong winds" in coastal and marine habitats ${ }^{10}$. The humeral and ulnar bone walls of Archaeopteryx, comparatively thinner than those of any element in the non-volant sample, reveal a strong affinity with volant birds but disqualify this taxon as a wing-propelled diver ${ }^{18}$ or obligatory "wind-assisted" flyer ${ }^{19}$.

Mass-normalised torsional resistance. Because a lower relative cortical thickness positions bone material further away from the bone section centroid (Supplementary Fig. 2) than a higher relative cortical thickness at the same amount of bone present, relative cortical thickness and mass-normalised torsional resistance are inherently not completely decoupled. Furthermore, mass-normalised torsional resistance retains a small yet significant allometric effect that reflects the inherent proportional relation between flight adaptations and body size, and should thus not be removed when investigating the locomotory affinities of extinct taxa ${ }^{12,20}$. Nevertheless, we focus on obvious signals and trends that exist relative to such relations, since those are particularly informative towards distinguishing the effects of related locomotory regimes.

Mass-normalised torsional resistance successfully separates non-avian theropods from flightless birds with comparable body mass values, but also exhibits subtle variation across avian flight modes (Supplementary Figs. 4 and 5). Burst-flying ${ }^{20}$ birds (incidental explosive take off and brief horizontal flight followed by a running escape) exhibit humeral and ulnar relative torsional resistance values overlapping with those of intermittent bounding ${ }^{20}$ flyers (flapping phases aimed at gaining altitude and speed, alternated with passive phases with folded wings). However, burst-flying ${ }^{20}$ birds attain body mass values that are, on average, two orders of magnitude higher than those of intermittent bounding ${ }^{20}$ flyers, which is informative when discriminating these two groups. Conversely, flap-gliding 20 birds have a similar to higher humeral and ulnar relative torsional resistance compared to burst ${ }^{20}$-adapted and most continuously flapping ${ }^{20}$ flyers at body masses that are, on average, one order of magnitude lower. Notably, the two large non-domesticated anatids in our data set share elevated relative torsional resistance values compared to other continuously flapping birds. Soaring birds ${ }^{20}$ may attain comparatively high body mass values, yet exhibit distinctly elevated normalised torsional resistance values relative to their body mass throughout (Supplementary Figs. 4 and 5).

The fifth, seventh, and ninth specimens of Archaeopteryx have reconstructed body mass values of 158,254 and $456 \mathrm{~g}^{13}$, respectively. These inferred ontogenetic ${ }^{13}$ mass differences do not scale linearly with humeral and ulnar torsional resistance: the seventh and ninth specimen exhibit comparable masscorrected torsional resistance values that are elevated proportional to those of the fifth specimen and within the lower range of modern volant birds. This may reflect an ontogenetic ecomorphological shift between the ages associated with reconstructed body mass values of 158 and $254 \mathrm{~g}$ towards increased volant adaptation. The seventh and ninth specimens of Archaeopteryx exhibit relative humeral torsional resistance approaching those of modern short ${ }^{21} /$ burst $^{20}$ flying birds of similar mass and higher than some heavier non-volant archosaurs. Ulnar torsional resistance values in these specimens are comparable to those of lighter volant birds and much heavier non-volant birds, and are higher than in the small non-avian coelurosaur Compsognathus. A shared proportional disparity between relative humeral and ulnar torsional resistance in the seventh and ninth specimen of Archaeopteryx with respect to flying birds indicates an underlying different employment of the epipodium, such as a possible larger contribution of the radius in wing load transfer to the humerus relative to the modern avian flight apparatus. Like Archaeopteryx, humeral and ulnar relative torsional resistance of Rhamphorhynchus, circa $40 \%$ lighter than the fifth specimen of Archaeopteryx, also scale with the lightest volant birds that have body masses up to one order of magnitude lower. The piscivorous diet of Rhamphorhynchus ${ }^{22}$ strongly favours active flight, and specimens substantially smaller than the individual considered here have been concluded to have been volant ${ }^{23}$. This, in turn, demonstrates that comparatively low relative torsional resistance of the bones supporting the limb carrying the airfoil does not preclude the capacity of active flight.

Volancy. Phylogenetic Principal Component Analysis (pPCA) of the referred parameters places Archaeopteryx in a domain shared almost exclusively with modern volant birds (Supplementary Fig. 7). Partitioning Around Medoids (PAM) of the first three phylogenetic Principal Components resolves volancy with a 95.52\% success rate and allies Archaeopteryx with volant archosaurs (Supplementary Data 2). Only three volant but (incidentally) wing-propelled diving birds were misclassified as flightless through their elevated relative cortical thickness. This outcome, including misclassification of the three wing-propelled divers and 


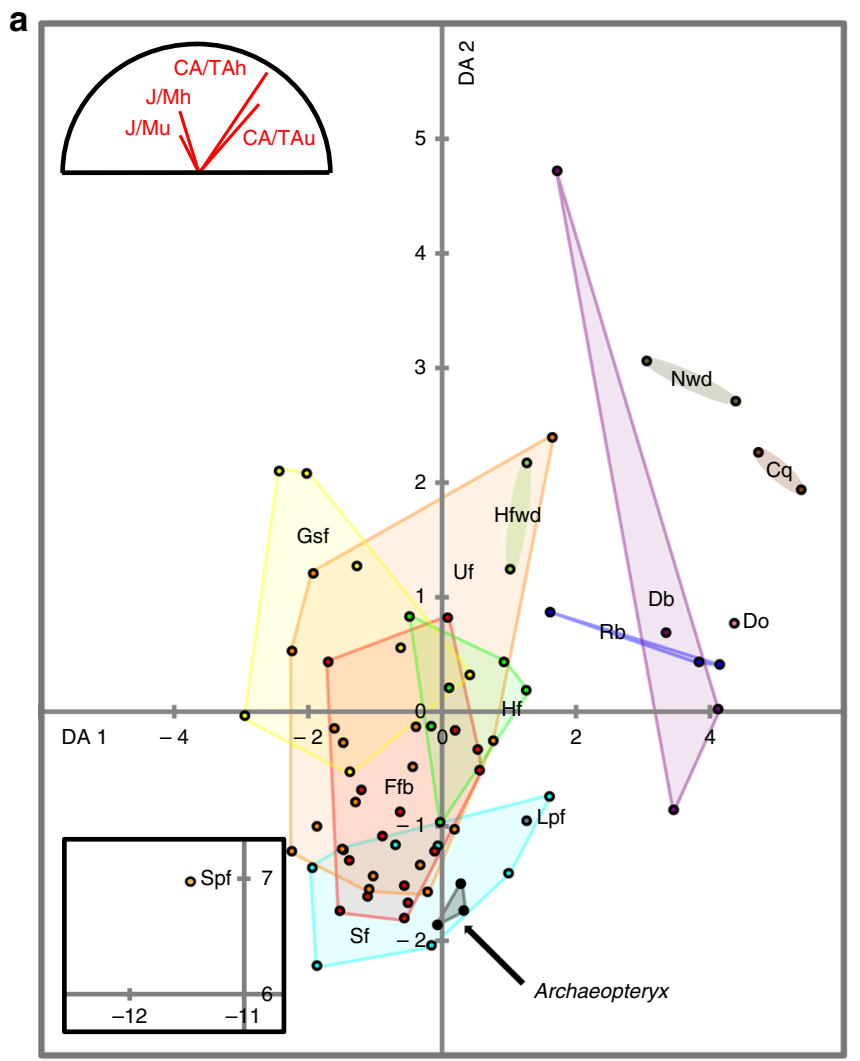

\author{
- Crocodilian quadrupedal \\ ○ Long-tailed pterosaurian flight \\ o Short-tailed pterosaurian flight \\ - Dinosaurian omnipedal \\ - Dinosaurian bipedal

\section{- Archaeopteryx} \\ - Non-volant wing-propelled diving \\ - High-frequency flapping flight and \\ wing-propelled diving \\ - Ratite bipedal \\ o Short flight \\ - Forward flapping and \\ bounding flight \\ - High-frequency \\ flapping flight \\ - Undulating flight
}

o Gliding-soaring flight

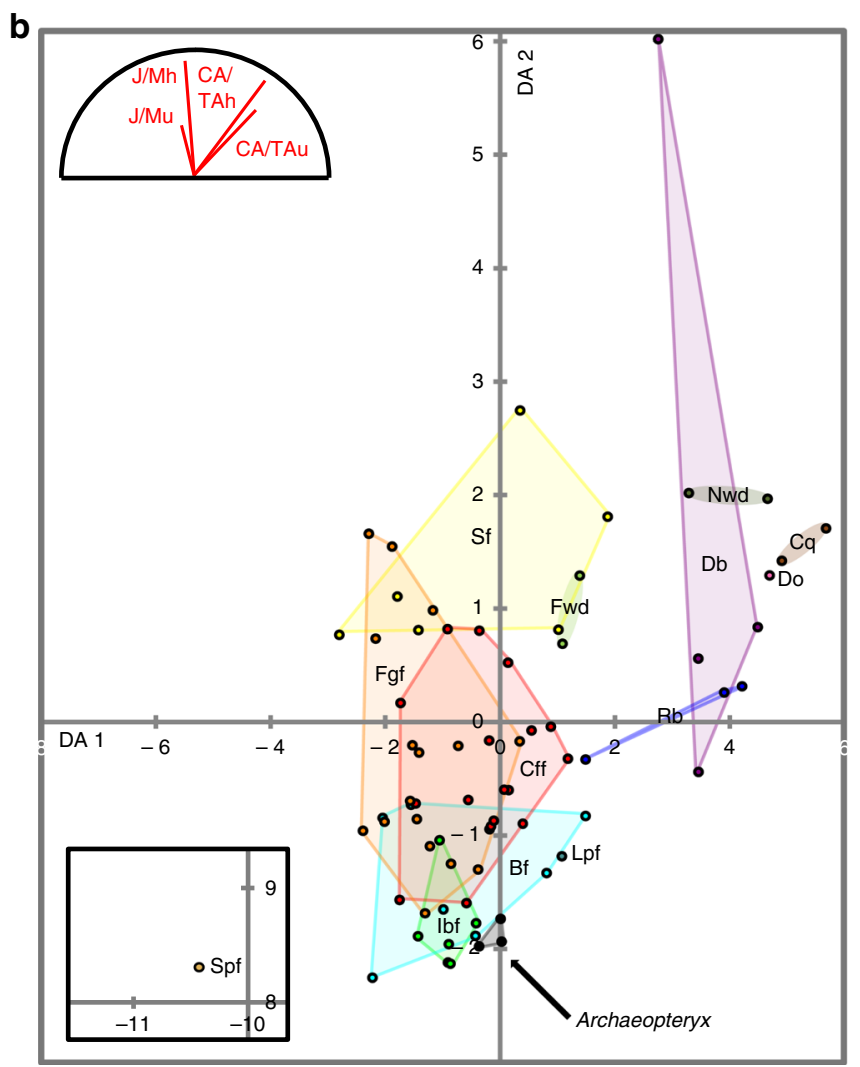

- Crocodilian quadrupedal

○ Long-tailed pterosaurian flight

○ Short-tailed pterosaurian flight

- Dinosaurian omnipedal

- Dinosaurian bipedal

- Archaeopteryx

- Non-volant wing-propelled diving

○ Flapping flight and wing-propelled diving

- Ratite bipedal

o Burst flight

○ Intermittent bounding flight

- Continuous flapping flight

○ Flap-gliding flight

○ Soaring flight

Fig. 2 LDA plot for specific archosaurian humeral and ulnar CA/TA and J/M. First and second linear discriminant axes are presented. Classification follows the locomotory divisions adapted from a Viscor et al. ${ }^{21}$ and $\mathbf{b}$ Close et al. ${ }^{20}$, non-pterosaurian flight strategies represent avian flight modes. Dots correspond to species, Archaeopteryx specimens plotted individually. Coloured hulls delimit groups with a minimum of three representatives; coloured ellipses link the members of groups with two representatives. Parameters labelled "_h" and "_u" in loading biplots designate humeral and ulnar affinity, respectively 
the assignment of Archaeopteryx to the volant group, is identically recapitulated by k-means clustering of the raw parameter values into two clusters (Supplementary Data 2). Additional discussion of volancy in Archaeopteryx through individual parameters is included in Supplementary Note 2.

Locomotor mode. Phylogenetic autocorrelation was found to be insignificant towards Phylogenetically Informed Discriminant Analysis (Supplementary Fig. 8), thus rendering Linear Discriminant Analysis (LDA) appropriate for resolving the locomotory affinity of Archaeopteryx. Linear discriminant analysis (LDA) principally separates volant and non-volant archosaurs along discriminant axis (DA) 1 (Fig. 2 and Supplementary Fig. 9) through predominantly humeral and ulnar relative cortical thickness. DA 2 is loaded more equally on all parameters than DA 1, but slightly stronger on relative cortical thickness for the classification expanded from Viscor et al. ${ }^{21}$, and slightly stronger on mass-normalised torsional resistance for the classification expanded from Close et al. ${ }^{20}$. Within modern volant birds, an overlapping succession of avian flight modes extends upwards along DA 2 (Fig. 2). This sequence starts at the bottom of DA 2 with short ${ }^{21}$ or burst ${ }^{20}$ flight and intermittent bounding ${ }^{20}$. These flight modes share a strong climbing component during powered flight phases, where intermittent bounding remains restricted to species with an adult body mass typically below $200 \mathrm{~g}^{21}$. Forward flapping ${ }^{21}$, high-frequency flapping $^{21}$, or continuous flapping ${ }^{20}$ flight is observed in birds that maintain level flapping flight after take-off. The avian sequence terminates in undulating ${ }^{21}$ or flap-gliding ${ }^{20}$ fliers that structurally alternate between flapping and gliding during flight, and aerial specialists in the gliding-soaring ${ }^{21}$ and soaring ${ }^{20}$ flight categories that harvest atmospheric movements to gain altitude and engage in sustained gliding. Across avian flight strategies and relative to mass-specific effects, relative torsional resistance of wing bones appears to scale inversely with a reliance on flapping during flight. This may reflect either a multidirectional stress regime or elevated torsional loading experienced during gliding and soaring as opposed to the directionally confined stresses associated with flapping ${ }^{12}$. A coupled decrease in relative cortical thickness and torsional resistance of anterior limb bones accompanied the transition from non-avian dinosaurs to birds (Fig. 2). A subsequent increase in relative torsional resistance at rather constant relative cortical thickness within volant birds accompanies the establishment of distinct avian flight modes (Fig. 2). Although basal and derived pterosaurs are represented by only one taxon each, their reciprocal relationship in pPCA and LDA morphospace qualitatively agrees with those between (occasionally) flapping birds and avian hyperaerial soarers, respectively. From a biomechanical point of view, this lends some support for an analogous evolutionary trajectory leading from flapping volancy in Rhamphorhynchus to an affinity with prolonged soaring in Brasileodactylus.

Discriminant classification unanimously groups the specimens of Archaeopteryx with short ${ }^{21}$ or burst ${ }^{20}$ flyers in our set (Supplementary Data 2). Substantial group overlap within the volant avian cluster in discriminant morphospace results in relatively low percentages of correctly classified training species (53.62\% and $56.52 \%$ for the Viscor et al. ${ }^{21}$ and Close et al. ${ }^{20}$ divisions, respectively), and this uncertainty undoubtedly carries over to the characterisation of extinct taxa with unknown locomotory strategies. Nevertheless, the position of Archaeopteryx is chiefly shared with short ${ }^{21} /$ burst $^{20}$ flyers (Fig. 2 and Supplementary Fig. 9), which supports the resolved affinity with these near-synonymous flight groups. Although Archaeopteryx plots close to intermittent bounding ${ }^{20}$ birds as well, its reconstructed adult body mass ${ }^{13}$ vastly exceeds the mass threshold to which modern bounding birds adhere ${ }^{21}$. Finally, short $^{21}$ and burst ${ }^{20}$ flyers exhibit significantly deviating means from respectively gliding-soaring 21 , and flap-gliding 20 and soaring ${ }^{20}$ birds (Supplementary Tables 1 and 2), thereby underlining an affinity to habitual flapping for Archaeopteryx.

\section{Discussion}

Obligatory gliding (non-serpent) amniotes, such as the extant flying lizard Draco and flying squirrels in the family Pteromyini, converge on the employment of typically low-aspect-ratio limbsupported patagia along the lateral body wall that are occasionally supplemented with webbed digits ${ }^{24}$. The pterosaurian and chiropteran flight apparatus superficially resemble derived, powered modifications of this general configuration that achieved active flight. In contrast, even the oldest avian wings represent specialised anterior limbs that are inherently mobile and structurally connect to the body exclusively through articulation with the glenoid. Such a particular modification of the non-avian maniraptoran arm, which constitutes a highly dexterous limb in its own right $^{25}$, sharply disagrees with the conventional condition shared by limbed amniotes primarily adapted to passive gliding. This advocates the employment of an actively moved wing in Archaeopteryx.

Earlier conclusions that Archaeopteryx was capable of active flight $^{26}$ have not received universal support, largely because three skeletomorphological conditions considered essential for a functional avian flight stroke (ossified, keeled sternum; supracoracoideal "pully" arrangement; glenohumeral tolerance permitting supradorsal humeral abduction) were not yet present in Archaeoptery $x^{26-30}$. Such challenges in reconciling Archaeopteryx's dromaeosaurid-like pectoral morphology ${ }^{30}$ with the modern avian dorsoventral flight stroke exemplify that avian powered flight may have worked through alternative configurations in the past. A putative aerodynamic control function for the long, stiff, frondfeathered tail ${ }^{2}$ and hindlimb plumage ${ }^{31}$ argue for an alternative aerial posture compared to modern birds. Archaeopteryx's large coracoids $^{30}$ and robust, flattened and more dorsally positioned furcula lacking hypocleidial communication with the sternum ${ }^{2}$ could have provided support for an anterodorsally-posteroventrally oriented flight stroke cycle that was morphologically closer to the "grabbing" motion of maniraptorans ${ }^{25}$ and did not or hardly extend over the dorsum.

The avian nature of Archaeopteryx's humeral and ulnar crosssectional geometry shares more flight-related biomechanical and physiological adaptations with modern volant birds than previously known, which we argue to reflect the shared capability of powered flight. Confuciusornis from the Early Cretaceous of China also lacked the supracoracoideal pully ${ }^{30}$ and sufficient dorsal humeral excursion ${ }^{5}$ to permit a modern avian flight stroke. However, a variety of Early Cretaceous enantiornitine and euornithine birds (Supplementary Fig. 1) was likely already capable of executing a dorsoventral wingbeat cycle $^{3,5,30}$, which suggests that the development of dorsoventral flapping is primitive for Ornithothoraces and approximately coincided with the appearance of the avian alula ${ }^{3}$. The origin of the modern avian flight stroke was conceivably promoted by selective pressure towards vertical take-off ${ }^{30}$, which contributed to the prosperous avian radiation that continued ever since.

\section{Methods}

Materials. Specimens of Archaeopteryx in this study are designated through a commonly used numerical sequence that roughly corresponds to their succession of discovery ${ }^{2}$. The fifth specimen of Archaeopteryx ${ }^{2}$ (JM 2257) is a nearly complete and largely articulated skeleton of the smallest Archaeopteryx specimen known to 
date. It is also known as the Eichstätt Specimen and housed at the Jura Museum in Eichstätt, Germany (JM). The seventh specimen of Archaeopteryx ${ }^{2}$ (BSP 1999 I 50) is represented by a comparably complete skeleton exhibiting a substantial degree of articulation. It is formally named Solnhofen-Aktien-Verein Specimen but generally referred to as Munich Specimen, and is kept at the Paläontologisches Museum München in Munich, Germany (PMM). Skeletal elements of both the fifth and seventh specimen of Archaeopteryx have experienced brittle deformation during post-depositional compaction that resulted in splintering of the bone cortex. The ninth specimen of Archaeopteryx ${ }^{2}$ (BMMS-BK1a) preserves a partially disarticulated right wing skeleton of comparably large size that is presently housed at the Bürgermeister-Müller-Museum in Solnhofen, Germany (BMM). It is officially named "Exemplar der Familien Ottman \& Steil", also known as

Bürgermeister-Müller Specimen, and colloquially referred to as "Chicken Wing". Although a certain degree of post-depositional compaction is evidenced by the presence of several fractures that propagate through the long bone cortex, cortical splintering has not occurred. Its elements have therefore largely preserved their original three-dimensional geometry ${ }^{2}$.

Comparative material (Supplementary Data 1) was sourced from the collections of the European Synchrotron Radiation Facility, Grenoble, France (ESRF), the Musée des Confluences, Lyon, France (MdC), the Muséum national d'Histoire naturelle, Paris, France (MNHM), the Museum of Evolution, Uppsala, Sweden (MoE), and the University of Manchester, Manchester, England (TUoM).

Data acquisition. The humeral and ulnar cross-sectional geometry of the three specimens of Archaeopteryx, 28 species of neornithine birds, the small coelurosaur Compsognathus longipes, the rhamphorhynchid pterosaur Rhamphorhynchus sp., the anhanguerid pterosaur Brasileodactylus araripensis, and the crocodile Crocodylus niloticus were visualised through propagation phase-contrast synchrotron $\mathrm{X}$ ray microtomography (PPC-SR $\mu \mathrm{CT}$ ) at beamlines BM05 and ID19 of the European Synchrotron Radiation Facility. An ulnar cross section of aff. Deinonychus antirrhopus was imaged and subsequently paired with a humeral section of $D$. antirrhopus from literature ${ }^{32}$ through morphological and dimensional comparison.

Synchrotron X-ray tomography was conducted by utilising an optimised polychromatic beam with sufficient coherence to permit the application of PPCSR $\mu$ CT. Propagation phase-contrast imaging relies on a certain propagation distance between the sample and the detector that allows for the exploitation of the phase-contrast effect towards emphasising low-contrast features ${ }^{33}$. The fifth and seventh specimen of Archaeopteryx were imaged in accumulation mode, a novel acquisition protocol developed for imaging fossils encased in lithic slabs. The motivation for and implementation of the accumulation mode are explained in Supplementary Note 1 Further details of the adopted data acquisition parameters for each sample are provided in Supplementary Data 3.

\section{Data processing. Three-dimensional volume reconstruction was conducted} through filtered back projection following a phase retrieval protocol that relies on a homogeneity assumption by using a modified ${ }^{33}$ version of the algorithm developed by Paganin et al. ${ }^{34}$. Virtual two-dimensional cross-sectional slides were extracted directly from the reconstructed volumes at the developmental mid-diaphyseal plane oriented perpendicular to the local bone long axis in VGStudio MAX 2.2 (Volume Graphics, Heidelberg, Germany). Avian ulnae that carry a quill knob (ulnar papilla) at mid-diaphysis were virtually sampled at the level nearest to middiaphysis where no quill knob was present. The data set was supplemented with avian samples used in earlier studies ${ }^{8,10,35}$. Furthermore, scaled figures depicting complete perpendicular humeral and ulnar cross sections of avian and non-avian archosaurs were sourced from literature $e^{17,36-39}$ and processed in tandem with data obtained through PPC-SR $\mu$ CT.

Cross-sectional geometry. Based on the characteristically unfolded nature of the Solnhofen Plattenkalk ${ }^{40}$, the geometry of Archaeopteryx wing elements was assumed to have experienced only brittle deformation during unidirectional compaction with insignificant movement of bone fragments perpendicular to the visualised cross sections. Two-dimensional restoration was conducted with image editing software by virtual extraction of the bone fragments and visually applying optimal fit of local fracture geometry, periosteal and endosteal curvature across adjacent fragments, and internal structures (e.g., canalisation). For the ninth specimen of Archaeopteryx, humeral and ulnar parameters were obtained by averaging the values found for two reconstructed circa mid-diaphyseal cross sections each. As the humeral and ulnar geometry of the fifth and seventh specimen are distorted to a markedly larger degree than those of the ninth specimen, they are represented by the single best-preserved cross section present in the circa mid-diaphyseal domain.

The elements of Compsognathus and Rhamphorhynchus used in this study were recovered from the Solnhofen Plattenkalk as well, and were reconstructed following the same protocol as the Archaeopteryx material (Supplementary Fig. 10). One fragment of cortical bone is conspicuously absent at the optimal sample location for the Compsognathus ulna in the upper right quadrant of the bone in the extracted slide, as also evidenced by an ulnar cross section extracted $3.58 \mathrm{~mm}$ proximal to the used sample location (Supplementary Fig. 10). The geometry of this cortical fragment at the sample location was reconstructed through close comparison with the bone and fracture geometry visible in the referred more proximal cross section.

All transverse cross sections were converted to binary cortical bone profiles by tracing the periosteal and endosteal surfaces and subsequently filling the area of the original cortical bone white ${ }^{41}$. Occasionally occurring spongy bone and obvious irregularities, such as cracks or protruding splints, were digitally removed. The area of the few small splints in fossil material that could not be accurately repositioned in their exact original orientation was taken into account during restoration of typically the periosteal margin. Cross-sectional geometric parameters were calculated with MomentMacro 1.4 (http://www.hopkinsmedicine.org/fae/mmacro.html) in the public-domain image analysis software ImageJ (https://imagej.nih.gov/ij/).

Most species in our data set are represented by the humerus and ulna of a single adult individual, although some were included as a composite of elements sourced from two individuals, or as average values derived from elements from two, three or four individuals (see Supplementary Data 1). Individuals sampled in this study are believed to represent adults based on element size and bone structure. Archaeopteryx specimens are often considered to be juveniles, which has been specifically concluded for the specimens of Archaeopteryx included in this study through relative size and bone surface texture ${ }^{2,13}$. The sampled Compsognathus specimen was also reported to represent a juvenile individual ${ }^{42}$. The studied Rhamphorhynchus individual is of comparably small size, suggesting juvenility as well. Gender composition across the data set is generally unknown and was therefore not considered.

Locomotor modes and body mass. Avian flight mode categorisation notoriously suffers from the qualitative, non-discrete nature of faunal flight strategies $^{20}$. To overcome classification-specific effects in discriminant analysis, we considered the classifications suggested by Viscor et al..$^{21}$ and Close et al. ${ }^{20}$ independently. Both avian flight mode divisions were expanded with one group that encompasses volant wing-propelled diving auks, and supplemented with alternative archosaurian locomotory strategies represented by exemplary taxa (Supplementary Data 1). The avian flight mode categories sensu Viscor et al. ${ }^{21}$ encompass (1) short flight, (2) forward flapping/bounding flight, (3) high-frequency flapping flight, (4) undulating flight and (5) gliding-soaring flight, which were assigned following the proposed taxonomical designations $^{21}$. Taxa not included in their work were assigned flight modes according to the provided description ${ }^{21}$. Geococcyx californianus was classified as 'short flight' rather than as 'forward flapping/bounding flight' proposed for Cuculidae. A second, more recent avian flight mode division by Close et al. ${ }^{20}$ separates (1) burst flight, (2) intermittent bounding flight, (3) continuous flapping flight, (4) flap-gliding flight and (5) soaring flight, and was applied through description. We chose to score volant wing-propelled divers separately in both subdivisions as their aquatic locomotory strategy is known to profoundly influence wing bone morphology ${ }^{17,43}$ and, consequently, the expression of flight-related adaptations recorded therein ${ }^{43}$. Both referred avian flight classifications were complemented with the following locomotor categories: (6) long-tailed pterosaurian flight, (7) short-tailed pterosaurian flight, (8) (avian) non-volant wing-propelled diving, (9) ratite bipedal, (10) (non-avian) dinosaurian bipedal, (11) (non-avian) dinosaurian omnipedal and (12) crocodilian quadrupedal.

Body mass values for extant taxa were either directly available for the referred individuals or sourced from online databases ${ }^{44,45}$ and literature ${ }^{46,47}$ as species averages (see Supplementary Data 1). For extinct forms, either specimen-specific body mass estimates ${ }^{13,39,48}$ or average specific body mass estimates were available $^{49,50}$. The Malagasy shelduck Alopochen sirabensis, reported to have been "slightly larger" than the Egyptian goose Alopochen aegyptiaca ${ }^{51}$ (average body mass of $1900 \mathrm{~g}^{44}$ ), was assigned a reconstructed body mass of $2000 \mathrm{~g}$. Body mass for the Rhamphorhynchus sp. MdC 20269891 was reconstructed through the relation between body mass and wing span for basal pterosaurs proposed by Witton $^{52}$. Total wing length for MdC 20269891 was measured as the cumulative length of the humerus $(19 \mathrm{~mm})$, radius $(34 \mathrm{~mm})$, wing metacarpal $(14 \mathrm{~mm})$, phalange I $(47 \mathrm{~mm})$, phalange II $(40 \mathrm{~mm})$, phalange III $(35 \mathrm{~mm})$ and phalange IV $(44 \mathrm{~mm})$ taken from photographic and scan data, and amounts to $233 \mathrm{~mm}$. In the Dark Wing specimen of Rhamphorhynchus muensteri (JME SOS 4785; Jura Museum Eichstätt), the distance between left and right glenoid measures $1.56 \times$ humeral length, which proposes an original interglenoid distance of $30 \mathrm{~mm}$ for for McD 20269891. Its corresponding wingspan, calculated as twice the wing length plus the interglenoid distance, amounts to $0.496 \mathrm{~m}$. From the relation of Witton ${ }^{52}$ follows a reconstructed body mass of $95 \mathrm{~g}$. The body mass for the Brasileodactylus araripensis individual in our study was inferred through close morphological and dimensional agreement between its humerus (length $168 \mathrm{~mm}$, maximum distal width of 47) and the humerus of AMNH 22552 (length $170 \mathrm{~mm}$, maximum distal width of $46 \mathrm{~mm})^{53,54}$, for which a reconstructed wingspan of $3270 \mathrm{~mm}$ was reported ${ }^{55}$. From the described relation between wingspan and body mass in pterodactyloids ${ }^{56}$ follows a reconstructed body mass of $6540 \mathrm{~g}$.

Body mass values for the studied specimens of Alligator mississippiensis (141 $\left.\mathrm{cm}^{38}\right)$ and the domestically bred Crocodylus niloticus $(200 \mathrm{~cm}$; personal observation PT) were reconstructed through specific allometric scaling relations between body length and body mass offered in literature ${ }^{57,58}$. 
Cross-sectional parameters. Relative cortical thickness ${ }^{12}$ (CA/TA) and massnormalised resistance against torsional forces ${ }^{12}(\mathrm{~J} / \mathrm{M})$ were quantified for archosaurian humeri and ulnae (Supplementary Data 1, Supplementary Figs. 4 and 5). CA/TA describes element hollowness as the ratio of cortical bone area to the total area delimited by the external surface of the bone in cross section (Supplementary Fig. 2). As such, CA/TA is proportionate to the corticodiaphysary index (CDI $)^{59}$ and inversely related to the K-parameter ${ }^{6,10}$. Polar moment of inertia of an area J quantifies the mechanical resistance against torsion around the longitudinal axis of the considered element. J mathematically equals the sum of the maximum second moment of area (Imax) and minimum second moment of area (Imin) that quantify resistance against deflection along the respective orthogonal major and minor principal axes (Supplementary Fig. 2) through the relative distribution of matter ${ }^{12}$. Values for J obtained from cross sections with an Imax/Imin $>1.50$ are typically overestimated ${ }^{12,60,61}$, but remain informative when considered proportionally rather than quantitatively (as is its derivative $\mathrm{Zp}^{41,61}$ ). J was normalised over body mass to permit comparison in a highly body mass-diversified comparative framework that spans well over five orders of magnitude (Supplementary Data 1 ).

Cortical vascular density, expressed as the amount of canals per $\mathrm{mm}^{2}$ of bone area in cross-section ${ }^{62-65}$, was considered qualitatively for a modest selection of archosaurs for which high-resolution data was available, but not challenged statistically (Supplementary Data 1). Bone area in section was calculated as CA (see 'Cross-sectional geometry' above) with MomentMacro 1.4 in ImageJ 1.49. In the fifth and ninth specimen of Archaeopteryx, cortical canals were counted visually. Absolute canal abundance in the cross-sectional cortex of archosaurs other than Archaeopteryx was obtained through selection of the darkest grey levels in the greyscale histogram (including canals) by thresholding the cortical domain and subsequently counting the amount of elements within canal size range using the Analyse Particles function of ImageJ 1.49

The ratio of Imax over Imin provides a reliable measure for the ellipticity of the transverse bone shaft and has been considered as such in biomechanical explorations ${ }^{12,60,66,67}$. These approaches traditionally assume that the degree and orientation of ellipticity reflect an adaptation that offers optimised resistance against bending, with the direction of Imax corresponding to the orientation of the maximum bending moment. However, an opposite functional interpretation of cross-sectional element ellipticity in which a preferred bending direction is achieved through orientation of Imin has also been proposed specifically for avian wing bones ${ }^{68}$. Such conflicting explanations of the same parameter illustrate the complexity of interpreting cross-sectional bone ellipticity in a functional context and thereby obscure the information offered by other characters when assessed in a multivariate context. We therefore chose not to include quantified bone ellipticity measures in our comparative study.

Tree inference and divergence chronogram. Mesozoic topology and timing used in this study (Supplementary Data 3 and Supplementary Fig. 1) were derived from the Paleobiology Database (PaleoDB; https://paleobiodb.org) on 29 January 2016. Divergence nodes were adopted as the older bound date for the oldest report of a taxon nested beyond the respective split. Mesozoic terminal nodes and the Tertiary terminal node for Mancalla cedrosensis were placed at the younger bound date of their occurrence. Alopochen sirabensis is placed at $656 \mathrm{AD}$, which represents the median calibrated radiocarbon age for the lastoccurrence date for the species ${ }^{69}$. The 19th century terminal node for Pinguinus impennis was dated through its well-documented last observation in $1844 \mathrm{AD}^{70}$. Topology and timing within the extant avian subset were largely adopted from the well-resolved phylogeny by Jarvis et al. ${ }^{71}$ (Supplementary Data 4 and Supplementary Fig. 1), since the more recent neoavian phylogeny proposed by Prum et al. ${ }^{72}$ was found to conflict PaleoDB on numerous crucial accounts. Several higher-order divergence times in Aves were obtained from PaleoDB following the procedure described above. Two specific inconsistencies in PaleoDB were negotiated through literature (see Supplementary Note 3). Insufficiently resolvable divergence nodes were placed at a standard $+4 \mathrm{MY}$ with respect to their closest established crownward node. The three Archaeopteryx specimens were included as a polytomy at $+4 \mathrm{MY}$ with respect to the older bound date for the genus in recognition of taxonomic and ontogenetic uncertainty ${ }^{2}$. The phylogenetic tree was constructed in Mesquite 3.04

Statistical analyses. The relations between individual geometric parameters and locomotor divisions in the training taxa set were statistically assessed through phylogenetic analysis of covariance using the PDAP module of Garland et al. ${ }^{74}$. For each parameter, 10000 unbound simulations were performed along the constructed tree (Supplementary Fig. 1) under a Brownian motion regime in PDSIMUL. ANCOVA was performed with a grouping of the training taxa according to their locomotor classes as response variable, parameter values as predictor variable, and body mass as covariate (Supplementary Data 5 ).

Phylogenetic PCA ${ }^{75}$ scores for the studied taxa, founded on humeral and ulnar $\mathrm{CA} / \mathrm{TA}$ and J/M (Supplementary Data 2), were obtained with the phyl.pca function (method: BM; mode: cor) of the phytools package ${ }^{76}$ in the R-environment ${ }^{77}$ through RStudio $0.99 .484^{78}$. The phylogenetic PCA scores were subsequently subjected to Partitioning Around Medoids specified to two clusters with the pam function of the cluster package ${ }^{79}$ in RStudio 0.99 .484 .
The archosaurian groups outside Archaeopteryx serve as training taxa that represent known locomotor modes and thus form a morphological reference environment for discriminant analysis. The optimum value of Pagel's $\lambda$, the scaling factor of autocorrelation for a certain parameter on a given phylogenetic tre $e^{80}$ to be applied in phylogenetically informed discriminant analysis, was found using the approach described by Schmitz et al..$^{81}$ in RStudio 0.99.484 (Supplementary Fig. 8). Linear discriminant analysis and classification of mystery taxa (Supplementary Data 2) was conducted in PAST $3.10^{82}$, as was one-way MANOVA

(Supplementary Tables 1-3) among individual locomotor strategies. Additional motivation for and information on the statistical approach used here is available as Supplementary Note 4

Data availability. All data underlying the study are available in Supplementary Data 1 .

Received: 30 July 2017 Accepted: 31 January 2018

Published online: 13 March 2018

\section{References}

1. Ksepka, D. T. Evolution-a rapid flight towards birds. Curr. Biol. 24, 1052-1055 (2014).

2. Wellnhofer, P. Archaeopteryx. Der Urvogel von Solnhofen (Dr Friedrich Pfeil, München, 2008).

3. Chiappe, L. M., Qingjin, L. M. Birds of Stone. Chinese Avian Fossils from the Age of Dinosaurs (John Hopkins University Press, Baltimore, 2016).

4. Burgers, P. \& Chiappe, L. M. The wing of Archaeopteryx as a primary thrust generator. Nature 399, 60-62 (1999).

5. Mayr, G. Avian Evolution. The Fossil Record of Birds and Its Paleobiological Significance (Wiley Blackwell, Chichester, 2017).

6. Currey, J. D. \& Alexander, R. The thickness of the walls of tubular bones. J. Zool. 206, 453-468 (1985)

7. Frost, H. M. From Wolff s law to the Utah paradigm: Insights about bone physiology and its clinical applications. Anat. Rec. 262, 398-419 (2001).

8. Cubo, J. \& Casinos, A. Biomechanical significance of cross-sectional geometry of avian long bones. Eur. J. Morphol. 36, 19-28 (1998).

9. Pennycuick, C. J. Modelling the flying bird, Vol. 5 (Elsevier, Burlington, 2008)

10. De Margerie, E., Sanchez, S., Cubo, J. \& Castanet, J. Torsional resistance as a principal component of the structural design of long bones: Comparative multivariate evidence in birds. Anat. Rec. Part A 282A, 49-66 (2005).

11. Tafforeau, P. et al. Applications of X-ray synchrotron microtomography for non-destructive 3D studies of paleontological specimens. Appl. Phys. A 83, 195-202 (2006).

12. Simons, E. L. R., Hieronymus, T. L. \& O’Connor, P. M. Cross sectional geometry of the forelimb skeleton and flight mode in pelecaniform birds. $J$. Morphol. 272, 958-971 (2011).

13. Erickson, G. M. et al. Was dinosaurian physiology inherited by birds? Reconciling slow growth in Archaeopteryx. PLoS ONE 4, e7390 (2009).

14. Cubo, J., Le Roy, N., Martinez-Maza, C. \& Montes, L. Paleohistological estimation of bone growth rate in extinct archosaurs. Paleobiology 38, 335-349 (2012).

15. Montes, L. et al. Relationships between bone growth rate, body mass and resting metabolic rate in growing amniotes: a phylogenetic approach. Biol. J. Linn. Soc. 92, 63-76 (2007).

16. Chinsamy-Turan, A. The microstructure of dinosaur bone: deciphering biology with fine-scale techniques (John Wiley \& Sons, Baltimore, 2005).

17. Smith, N. A. \& Clarke, J. A. Osteological histology of the Pan-Alcidae (Aves, Charadriiformes): correlates of wing-propelled diving and flightlessness. Anat. Rec. 297, 188-199 (2014)

18. Ebel, K. On the origin of flight in Archaeopteryx and in pterosaurs. Neues Jahrb. für Geol. und Palaöntologie-Abh. 202, 269-285 (1996).

19. Thulborn, R. A. [Wind-assisted flight of Archaeopteryx]. Neues Jahrb. für Geol. und Palaöntologie-Abh. 229, 61-74 (2003).

20. Close, R. A. \& Rayfield, E. J. Functional morphometric analysis of the furcula in Mesozoic birds. PloS ONE 7, e36664 (2012).

21. Viscor, G. \& Fuster, J. F. Relationships between morphological parameters in birds with different flying habits. Comp. Biochem. Physiol. 87A, 231-249 (1987).

22. Hone, D., Henderson, D. M., Therrien, F. \& Habib, M. B. A specimen of Rhamphorhynchus with soft tissue preservation, stomach contents and a putative coprolite. PeerJ 3, e1191 (2015).

23. Bennett, S. C. A statistical study of Rhamphorhynchus from the Solnhofen Limestone of Germany: year-classes of a single large species. J. Paleontol. 69, 569-580 (1995). 
24. Socha, J. J., Jafari, F., Munk, Y. \& Byrnes, G. How animals glide: from trajectory to morphology. Can. J. Zool. 93, 901-924 (2015).

25. Gishlick, A. D. in New perspectives on the origin and early evolution of birds (eds. Gauthier, J. \& Gall, L. F.) 301-318 (Peabody Museum of Natural History, New Haven, 2001).

26. Olson, S. L. \& Feduccia, A. Flight capability and the pectoral girdle of Archaeopteryx. Nature 278, 247-248 (1979).

27. Zheng, X. et al. On the absence of sternal elements in Anchiornis (Paraves) and Sapeornis (Aves) and the complex early evolution of the avian sternum. Proc. Natl Acad. Sci. 111, 13900-13905 (2014).

28. Poore, S. O., Sánchez-Haiman, A. \& Goslow, G. E. Wing upstroke and the evolution of flapping flight. Nature 387, 799-802 (1997).

29. Senter, P. Scapular orientation in theropods and basal birds, and the origin of flapping flight. Acta Palaeontol. Pol. 51, 305-313 (2006).

30. Mayr, G. Pectoral girdle morphology of Mesozoic birds and the evolution of the avian supracoracoideus muscle. J. Ornithol. 158, 859-867 (2017).

31. Longrich, N. Structure and function of hindlimb feathers in Archaeopteryx lithographica. Paleobiology 32, 417-431 (2006).

32. Parsons, W. L. \& Parsons, K. M. Further descriptions of the osteology of Deinonychus antirrhopus (Saurischia, Theropoda). Bull. Buffalo Soc. Nat. Sci. 38, 43-54 (2009).

33. Sanchez, S., Ahlberg, P. E., Trinajstic, K. M., Mirone, A. \& Tafforeau, P. Threedimensional synchrotron virtual paleohistology: a new insight into the world of fossil bone microstructures. Microsc. Microanal. 18, 1095-1105 (2012).

34. Paganin, D., Mayo, S. C., Gureyev, T. E., Miller, P. R. \& Wilkins, S. W. Simultaneous phase and amplitude extraction from a single defocused image of a homogeneous object. J. Microsc. 206, 33-40 (2002).

35. Cubo, J. \& Casinos, A. Incidence and mechanical significance of pneumatization in the long bones of birds. Zool. J. Linn. Soc. 130, 499-510 (2000).

36. Werning, S. The ontogenetic osteohistology of Tenontosaurus tilletti. PLoS ONE 7, e33539 (2012).

37. White, M. A. et al. New forearm elements discovered of holotype specimen Australovenator wintonensis from Winton, Queensland, Australia. PloS ONE 7, e39364 (2012)

38. Woodward, H. N., Horner, J. R. \& Farlow, J. O. Quantification of intraskeletal histovariability in Alligator mississippiensis and implications for vertebrate osteohistology. PeerJ 2, e422 (2014).

39. Bybee, P. J., Lee, A. H. \& Lamm, E. T. Sizing the Jurassic theropod dinosaur Allosaurus: assessing growth strategy and evolution of ontogenetic scaling of limbs. J. Morphol. 267, 347-359 (2006).

40. Barthel, K. W., Swinburne, N. H. M., Conway Morris, S. Solnhofen. A study in Mesozoic palaeontology (Cambridge University Press, Cambridge, 1990).

41. Lee, A. H. \& Simons, E. L. R. Wing bone laminarity is not an adaptation for torsional resistance in bats. PeerJ 3, e823 (2015).

42. Callison, G. \& Quimby, H. M. Tiny dinosaurs: are they fully grown? J. Vertebr. Paleontol. 3, 200-209 (1984).

43. Habib, M. B. \& Ruff, C. B. The effects of locomotion on the structural characteristics of avian limb bones. Zool. J. Linn. Soc. 153, 601-624 (2008).

44. De Magalhaes, J. P. \& Costa, J. A database of vertebrate longevity records and their relation to other life-history traits. J. Evolut. Biol. 22, 1770-1774 (2009).

45. del Hoyo, J., Elliott, A., Sargatal, J., Christie, D. A., \& de Juana, E. Handbook of the Birds of the World Alive (Lynx Edicions, Barcelona, 2015).

46. Batty, J. Domesticated ducks and geese (Nimrod Book Services, 1985).

47. Mackie, R. \& White, B. (eds.) Gastrointestinal Microbiology, Vol. 1 In Gastrointestinal Ecosystems and Fermentations (Chapman and Hall, New York, 1997).

48. Paul, G. S. Predatory dinosaurs of the world: a complete illustrated guide (Simon \& Schuster, New York, 1988).

49. Livezey, B. C. Morphometrics of flightlessness in the Alcidae. Auk 105, 681-698 (1988).

50. Paul, G. S. The Princeton field guide to dinosaurs (Princeton University Press, Princeton, 2010).

51. Andrews, C. On some fossil remains of carinate birds from Central Madagascar. Ibis 39, 343-359 (1897).

52. Witton, M. P. in Special volume: Flugsaurier: pterosaur papers in honour of Peter Wellnhofer (eds. Buffetaut, E. \& Hone, D. W. E.) 143-158 (München, 2008).

53. Kellner, A. W. A. \& Tomida, Y. Description of a new species of Anhangueridae (Pterodactyloidea) with comments on the pterosaur fauna from the Santana Formation (Aptian-Albian), northeastern Brazil. Natl Sci. Mus. Monogr. 17, 1-135 (2000).

54. Veldmeijer, A. J. Pterosaurs from the Lower Cretaceous of Brazil in the Stuttgart Collection. Stuttg. Beitr. Nat. Ser. B. 327, 1-27 (2002).

55. Wellnhofer, P. Weitere Pterosaurierfunde aus der Santana-Formation (Apt) der Chapada do Araripe, Brasilien. Palaeontogr. Abt. A. 187, 43-101 (1991).
56. Henderson, D. M. Pterosaur body mass estimates from three-dimensional mathematical slicing. J. Vertebr. Paleontol. 30, 768-785 (2010).

57. Masser, M. P. Alligator production: grow-out and harvest. SRAC Publ. 232, 1-4 (1993).

58. Huchzermeyer, F. W. Crocodiles: Biology, Husbandry, and Diseases (CABI, Cambridge, 2003).

59. Castanet, J., Grandin, A., Abourachid, A. \& de Ricqlès, A. (1996). [Expression de la dynamique de croissance dans la structure de l'os périostique chez Anas platyrhynchos]. Comptes Rendus De. l'Académie Des. Sci.-Ser. III 319, 301-308 (1996).

60. Daegling, D. J. Estimation of torsional rigidity in primate long bones. J. Human. Evol. 43, 229-239 (2002).

61. Ruff, C. B., Burgess, M. L., Bromage, T. G., Mudakikwa, A. \& McFarlin, S. C. Ontogenetic changes in limb bone structural proportions in mountain gorillas (Gorilla beringei beringei). J. Human. Evol. 65, 693-703 (2013).

62. de Buffrénil, V., Houssaye, A. \& Böhme, W. Bone vascular supply in monitor lizards (Squamata: Varanidae): influence of size, growth, and phylogeny. $J$. Morphol. 269, 533-543 (2008)

63. Legendre, L. et al. Phylogenetic signal in bone histology of amniotes revisited. Zool. Scr. 42, 44-53 (2013).

64. Cubo, J., Baudin, J., Legendre, L., Quilhac, A. \& De Buffrénil, V. Geometric and metabolic constraints on bone vascular supply in diapsids. Biol. J. Linn. Soc. 112, 668-677 (2014).

65. Wilson, L. E. \& Chin, K. Comparative osteohistology of Hesperornis with reference to pygoscelid penguins: the effects of climate and behaviour on avian bone microstructure. R. Soc. Open Sci. 1, 140245 (2014)

66. Carlson, K. J. Investigating the form-function interface in African apes: relationships between principal moments of area and positional behaviors in femoral and humeral diaphyses. Am. J. Phys. Anthropol. 127, 312-334 (2005).

67. Patel, B. A., Ruff, C. B., Simons, E. L. R. \& Organ, J. M. Humeral crosssectional shape in suspensory primates and sloths: long bone cross-sectional shape. Anat. Rec. 296, 545-556 (2013).

68. Bertram, J. E. \& Biewener, A. A. Bone curvature: sacrificing strength for load predictability? J. Theor. Biol. 131, 75-92 (1988)

69. Turvey, S. T. (ed.) Holocene extinctions. (Oxford University Press, New York, 2009).

70. Bengtson, S.-A. Breeding ecology and extinction of the great auk (Pinguinus impennis): anecdotal evidence and conjectures. Auk 101, 1-12 (1984).

71. Jarvis, E. D. et al. Whole-genome analyses resolve early branches in the tree of life of modern birds. Science 346, 1320-1331 (2014).

72. Prum, R. O. et al. A comprehensive phylogeny of birds (Aves) using targeted next-generation DNA sequencing. Nature 526, 569-573 (2015).

73. Madison, W. P. \& Madison, D. R. Mesquite: a modular system for evolutionary analysis-Version 3.04 (2015). http://mesquiteproject.org (Accessed $29 \mathrm{Sep}$ 2015).

74. Garland, T., Dickerman, A. W., Janis, C. M. \& Jones, J. A. Phylogenetic analysis of covariance by computer simulation. Syst. Biol. 42, 265-292 (1993).

75. Revell, L. J. Size-correction and principal components for interspecific comparative studies. Evolution 63, 3258-3268 (2009).

76. Revell, L. J. phytools: an R package for phylogenetic comparative biology (and other things). Methods Ecol. Evol. 3, 217-223 (2012).

77. R. Core Team. A language and environment for statistical computing. ( $\mathrm{R}$ Foundation for Statistical Computing, Vienna, 2015).

78. R Studio Team R Studio: Integrated Development for R. R Studio, Inc. (2015).

79. Maechler, M., Rousseeuw, P., Struyf, A., Hubert, M. \& Hornik, K. Cluster analysis basics and extensions. R package version 2.0.4. CRAN (2016).

80. Pagel, M. Inferring the historical patterns of biological evolution. Nature 401, 877-884 (1999).

81. Schmitz, L. \& Motani, R. Nocturnality in dinosaurs inferred from scleral ring and orbit morphology. Science 332, 705-708 (2011).

82. Hammer, Ø., Harper, D. A. T. \& Ryan, P. D. [PAST: Paleontological statistics software package for education and data analysis]. Palaeontologia Electronica 4, 4 (2001).

\section{Acknowledgements}

The authors thank P.E. Ahlberg, V. Fernandez, D.J. Field, D. Hanley, A. Houssaye, G. Oatley, O.W.M. Rauhut, F.J. Serrano, and E.L.R. Simons for discussions or providing advice. D. Berthet (Musee des Confluences, Lyon, France), M. Eriksson (Museum of Evolution, Uppsala, Sweden), C.K. Lefèvre (MNHN, Paris, France) and J.R. Nudds (School of Earth and Environmental Sciences, University of Manchester, UK) are acknowledged for providing access to the material kept in their care. Beamtime was available as inhouse beamtime at the ESRF.

\section{Author contributions}

D.F.A.E.V., P.T. and S.S. conceived the study and designed the experiments, D.F.A.E.V., M.R., V.B., P.T. and S.S. performed the experiments, D.F.A.E.V., J.C., E.d.M. and S.S. 
analysed the data, D.F.A.E.V. wrote the manuscript, J.C., E.d.M., M.R., V.B., S.B., P.T and S.S. helped with and edited the manuscript.

\section{Additional information}

Supplementary Information accompanies this paper at https://doi.org/10.1038/s41467018-03296-8

Competing interests: The authors declare no competing interests.

Reprints and permission information is available online at http://npg.nature.com/ reprintsandpermissions/

Publisher's note: Springer Nature remains neutral with regard to jurisdictional claims in published maps and institutional affiliations. (c) (i) Open Access This article is licensed under a Creative Commons Attribution 4.0 International License, which permits use, sharing, adaptation, distribution and reproduction in any medium or format, as long as you give appropriate credit to the original author(s) and the source, provide a link to the Creative Commons license, and indicate if changes were made. The images or other third party material in this article are included in the article's Creative Commons license, unless indicated otherwise in a credit line to the material. If material is not included in the article's Creative Commons license and your intended use is not permitted by statutory regulation or exceeds the permitted use, you will need to obtain permission directly from the copyright holder. To view a copy of this license, visit http://creativecommons.org/ licenses/by/4.0/.

(C) The Author(s) 2018 